\title{
Simulation of solute transport under oscillating groundwater flow in homogeneous aquifers
}

\author{
AMRO M.M. ELFEKI, Associate Professor, Water Resources Section, TU Delft, PO Box 5048, 2600 GA Delft, The Netherlands \\ (Current address: Department of Water Resources, Faculty of Meteorology, Environment and Arid Land Agriculture, \\ King Abdulaziz. University, Jeddah, Saudi Arabia. Tel.: +966-50-4919254; fax: +966-2-6952367; e-mail: amro_elfeki@yahoo.com) \\ (author for correspondence)
}

GERARD J.M. UFFINK, Associate Professor, Geotechnical Laboratory, TU Delft, PO Box 5048, 2600 GA Delft, The Netherlands. Tel.: +31-15-2782628.

SOPHIE LEBRETON, M.Sc. Student, Water Resources Section, TU Delft, PO Box 5048, 2600 GA Delft, The Netherlands

\begin{abstract}
In this paper, we focus on the influence of temporal variations in the regional hydraulic gradient, particularly, on the impact of temporal variations in the boundary conditions on the spreading of solute plumes in homogenous aquifers. We examined the problem by numerical simulations. Twodimensional fully implicit finite difference model TRANS_GW_2D for the unsteady groundwater flow and a random walk particle tracking model TRANS_RW_2D for solute transport have been developed to solve the governing equations without restriction on the values of aquifer storativity or on the magnitude of the temporal fluctuations. It has been shown that transient flow conditions (in terms of gradient magnitude variability) have a significant impact on contaminant transport only if the amplitude and period of the oscillations are relatively large. For relatively small oscillations, a steady state flow field can be justified. Transient conditions may be relevant in coastal aquifers with high tidal amplitudes. This tidal variation can have an effect on the spreading of solutes and on salt-water intrusion. Our numerical experiments demonstrate that in case of relatively high storativity values, the dispersion coefficient is amplified in time as the plume moves towards the fluctuating boundary.
\end{abstract}

\section{RÉSUMÉ}

Keywords: Oscillating flow, solute transport, numerical modeling, groundwater, time dependent dispersion coefficient, spatial moments.

\section{Introduction}

Contamination of groundwater by chemicals is a worldwide environmental problem. Current concern and awareness of groundwater contamination problems have motivated studies of contaminant transport in porous media. Many studies assume a steady state flow field. However, natural flow systems are rarely in a steady state. Temporal fluctuations in the recharge or in the boundary conditions lead to variations in the velocity field that contribute to dispersive mixing. This behavior has been supported by many field observations (e.g. Gelhar, 1993).
Significant progress of steady groundwater flow in stationary random fields has been achieved (e.g. Smith and Freeze, 1979; Ababou et al., 1989; Gelhar, 1993) to study the influence of spatial variability on the spreading of solutes in porous media. Many researchers show still vivid interest to describe the influence of transient conditions on contaminant spreading. To the authors' knowledge, in the hydrogeological community, little attention is made on evaluating the effects of transient conditions (Goode and Konikow, 1990; Yim and Mohsen, 1992; Ross, 1999; Schirmer, et al., 2001). Two main transient conditions are causing the spreading of solutes that can be classified as the

Revision received xxx. Open for discussion till xxx. 
gradient magnitude variability (i.e. the changes in the magnitude of the head gradients in time) and the gradient direction variability [i.e the changes in the direction of the head gradients in time (Gelhar, 1993)]. Kinzelbach and Ackerer (1986) showed that temporal variations yields a larger transverse dispersivity, but smaller longitudinal dispersivity when compared with steady flow condition. Goode and Konikow (1990) found that directional variation in hydraulic gradient is more important than the magnitude variation in the hydraulic gradient.

Different form the work by Goode and Konikow (1990), in this paper, we focus on the influence of temporal variations in the magnitude of the hydraulic gradient, particularly, the impact of temporal variations of the head boundary conditions. We examined the problem by numerical simulations, using the governing equations without a restriction to the values of aquifer storativity or on the magnitude of the temporal fluctuations. A sensitivity analysis has been performed to study the influence of signals of single and compound periods, storativity of the aquifer, magnitude of the period of oscillations on the dispersive mixing of solute plumes.

\section{Numerical experiments and model verification}

We consider a homogeneous aquifer of a constant thickness with impermeable boundaries at the top and the bottom of the aquifer as shown in Fig. 1 (a, cross-section). At the left side (upstream boundary), a river of constant water level is feeding the aquifer. The main direction of the flow of water is from left to right. At the right side (downstream boundary), the water level is fluctuating with a given function. It should also be mentioned that lateral sides of the aquifer are also considered impermeable boundaries (see Fig. 1b, plan view). The influence of water level fluctuations



(a)

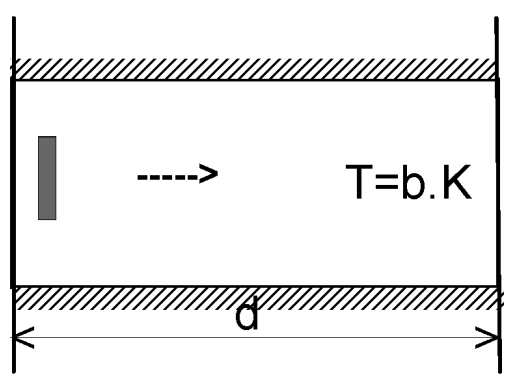

(b)

Figure 1 Sketch of flow and transport domain (a) aquifer cross-section, (b) aquifer plan with boundary conditions. Left boundary is called upstream boundary and right boundary is called downstream boundary. For system dimensions see Table 1. on the aquifer response and consequently on the transport of solute under these conditions are investigated.

For the groundwater flow, a numerical model based on a fully implicit finite difference numerical scheme has been developed to simulate transient flow in a confined aquifer (Elfeki, 2003). We consider simple boundary conditions in homogeneous and isotropic aquifer where analytical solutions exist for model verification. The differential equation which describes the flow in a confined aquifer of thickness $b$, storativity $S$ and conductivity $K$, is,

$$
\frac{\partial^{2} h}{\partial x^{2}}=\beta^{2} \frac{\partial h}{\partial t} \quad \text { with } \beta^{2}=\frac{S}{K b}
$$

where $h$ is the hydraulic head. The initial and boundary conditions of the hydraulic head are,

$$
\begin{aligned}
& h(0, t)=0 \\
& h(d, t)=h_{0} \cos (\omega t)
\end{aligned}
$$

where $h_{0}$ is the amplitude of the wave at the downstream boundary and $\omega$ is the angular frequency. The analytical solution is given by,

$$
\begin{aligned}
h(x, t)= & \frac{h_{0}}{\cosh ^{2}(d / l)-\cos ^{2}(d / l)} \\
& \times\left[\cos (\omega t) \sinh \left(\frac{x}{l}\right) \cos \left(\frac{x}{l}\right) \sinh \left(\frac{d}{l}\right) \cos \left(\frac{d}{l}\right)\right. \\
& -\sin (\omega t) \cosh \left(\frac{x}{l}\right) \sin \left(\frac{x}{l}\right) \sinh \left(\frac{d}{l}\right) \cos \left(\frac{d}{l}\right) \\
& +\sin (\omega t) \sinh \left(\frac{x}{l}\right) \cos \left(\frac{x}{l}\right) \cosh \left(\frac{d}{l}\right) \sin \left(\frac{d}{l}\right) \\
& \left.+\cos (\omega t) \cosh \left(\frac{x}{l}\right) \sin \left(\frac{x}{l}\right) \cosh \left(\frac{d}{l}\right) \sin \left(\frac{d}{l}\right)\right]
\end{aligned}
$$

where $l$ is called the penetration length defined as $1 / \beta \sqrt{2 \omega}=$ $\sqrt{T P / \pi S}$ where $T$ is the transmissivity $T=K b$, and $P$ is the wave period defined as $P=2 \pi / \omega$.

The data of the numerical experiments are tabulated in Table 1.

Figure 2 shows very good agreement between the numerical simulations and the analytical solution. Various tests of the model under different boundary conditions give also very good agreement (Lebreton, 2003).

Table 1 Simulation parameters used in flow computation

\begin{tabular}{ll}
\hline Parameter & Numerical value \\
\hline Domain dimensions & $200 \mathrm{~m} \times 50 \mathrm{~m}$ \\
Domain discretization & $1.0 \mathrm{~m} \times 1.0 \mathrm{~m}$ \\
Time step & 0.5 day \\
Upstream fixed head & $20 \mathrm{~m}$ \\
$\quad$ boundary & Given function \\
$\begin{array}{l}\text { Downstream boundary } \\
\text { Constant aquifer thickness }\end{array}$ & $10 \mathrm{~m}$ \\
$\begin{array}{l}\text { Homogeneous hydraulic } \\
\quad \text { conductivity }\end{array}$ & $10 \mathrm{~m} /$ day \\
Accuracy in computation & 0.001 \\
$\quad$ sum of head residuals $)$ & \\
$\begin{array}{l}\text { No. of time steps } \\
\text { Storage coefficient }\end{array}$ & $50 \mathrm{steps}(25$ days $)$ \\
\hline
\end{tabular}




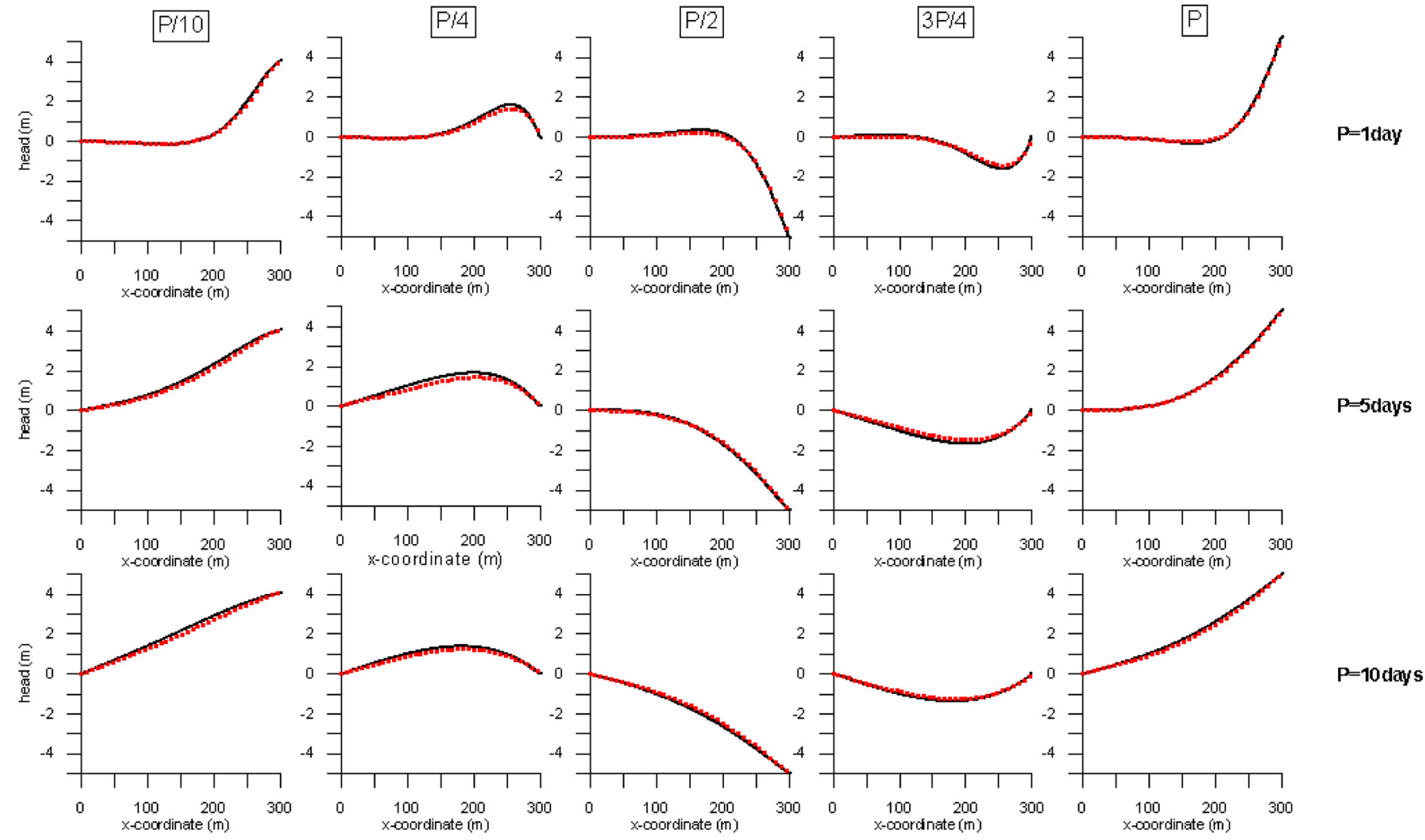

Figure 2 Head profiles along the aquifer length. Dots: numerical results, solid lines: analytical results. The downstream water level is a cosine function with an amplitude of $5 \mathrm{~m}$ and with different wave periods: 1, 5, 10 days. Aquifer characteristics: length $=300 \mathrm{~m}, S=0.01$.

The transport of solute in homogeneous isotropic aquifer under advection and dispersion processes is given by (Bear, 1979),

$$
\frac{\partial C}{\partial t}+\frac{\partial}{\partial x}\left(V_{x} C\right)=\frac{\partial}{\partial x}\left(D_{0, x x} \frac{\partial C}{\partial x}\right)+\frac{\partial}{\partial y}\left(D_{0, y y} \frac{\partial C}{\partial y}\right)
$$

where $C$ is the solute concentration, $V_{x}$ is the Darcy's velocity given by $V_{x}(x, t)=-K \nabla h(x, t) / \varepsilon$, where $\varepsilon$ is the aquifer porosity and $D_{0, x x}$ and $D_{0, y y}$ are pore-scale dispersion coefficients given by,

$$
D_{0, x x}=D_{\text {eff }}+\alpha_{\mathrm{L}}\left|V_{x}\right| \quad \text { and } \quad D_{0, y y}=D_{\text {eff }}+\alpha_{\mathrm{T}}\left|V_{x}\right|
$$

where $\alpha_{\mathrm{L}}$ is the longitudinal dispersivity, $\alpha_{\mathrm{T}}$ is the lateral dispersivity, and $D_{\text {eff }}$ is the diffusion coefficient which is neglected in our case.

The transport model is solved using the particle tracking random walk technique (Uffink, 1990),

$$
\begin{aligned}
& X_{p}^{n+1}=X_{p}^{n}+V_{x} \Delta t+\frac{\partial D_{x x}}{\partial x} \Delta t+Z \sqrt{2 \alpha_{\mathrm{L}}\left|V_{x}\right| \Delta t} \\
& Y_{p}^{n+1}=Y_{p}^{n}+\frac{\partial D_{y y}}{\partial y} \Delta t+Z^{\prime} \sqrt{2 \alpha_{\mathrm{T}}\left|V_{x}\right| \Delta t}
\end{aligned}
$$

where $X_{p}^{n+1}$ and $Y_{p}^{n+1}$ are the new $x$ - and $y$-coordinate of the particle $p, X_{p}^{n}$ and $Y_{p}^{n}$ are the old $x$ - and $y$-coordinate of the particle $p, V_{x} \Delta t$ is the advective movement of the particle in the $x$-direction, and $Z$ and $Z^{\prime}$ are two independent random numbers drawn from normal distribution.

The procedure to solve both flow and transport equations is as follows: at a given time step, the corresponding groundwater
Table 2 Transport simulation parameters

\begin{tabular}{ll}
\hline Transport simulation parameters & Values \\
\hline Location of the injection & $x=10 \mathrm{~m} \quad y=-25 \mathrm{~m}$ \\
Size of the source of contaminant & $1 \mathrm{~m} \times 1 \mathrm{~m}$ \\
Pore-scale longitudinal dispersivity & $\alpha_{\mathrm{L}}=0.5 \mathrm{~m}$ \\
Pore-scale lateral dispersivity & $\alpha_{\mathrm{T}}=0.05 \mathrm{~m}$ \\
Porosity & $\varepsilon=0.4$ \\
Injected mass & $2500 \mathrm{~g}$ \\
Number of particles & 100,000 \\
Time step & $\Delta t=1$ day \\
\hline
\end{tabular}

head is computed and then differentiated to compute the spatial variation of the velocity and then solve the above transport equation each time step with its local velocity field for each particle to compute the displacements of the particles and the particles spatial moments. Proceed with the next time step and repeat the computation.

\section{Sensitivity analysis of model parameters and results}

\subsection{Simple signal with one period}

The period of the fluctuations of the downstream water level affects the oscillations of the hydraulic heads and therefore the velocities within the aquifer. Long periods (or slow fluctuations) yield oscillations of the hydraulic head with a greater magnitude than short periods do, and this influence is propagated even far from the fluctuating boundary. This behavior can be observed 
in Fig. 2 where several flow simulations were carried out with different periods. It is also obvious that the penetration length $l=\sqrt{T P / \pi S}$ is the factor that control oscillations. The dependence of the physical response on the penetration length has also been addressed by Townley (1995) for a quite similar case. He shows that for a one-dimensional finite aquifer with a no-flow boundary at one side and periodic fluctuations on the other side, the amplitude and the propagation of the hydraulic head fluctuations depend on the ratio $d / l$ which is the length of the aquifer over the penetration length.

\subsection{Compound signal with two periods}

A numerical simulation was performed in order to study the influence of fast oscillations (high frequency) superimposed over slow oscillations (low frequency) on disperion (e.g. daily fluctuations of the river water level due to tides plus monthly fluctuations due to rainfall). A periodical fluctuation was imposed at the downstream boundary: the signal is given by, $h(d, t)=$ $20 \cos (2 \pi t / 40)+\cos (2 \pi t / 2)$. Oscillations of large and short periods are observed on the hydraulic head and Darcy's velocity over the entire length of the aquifer. Particles were injected in this flow field and results of the spatial moments (Fig. 3) show that short period oscillations vanish completely, while large period oscillations are still visible.
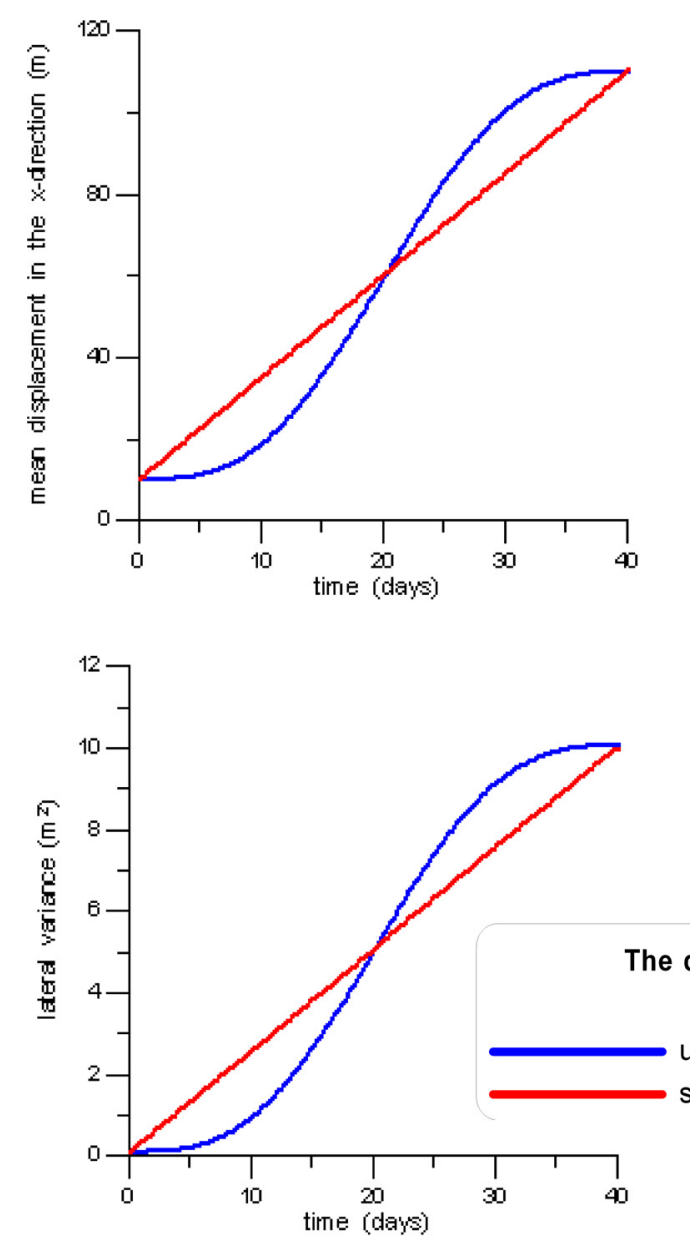

Figure 3 Spatial moments of the contaminant plume for the case of fast fluctuations (high frequency) superimposed over slow oscillations (low frequency).

\subsection{Influence of storativity}

A fluctuating head at the right boundary has been applied while keeping the left one at a constant water level for aquifers of different storativity. The downstream level is defined as follows: $h(d, t)=20 \times \cos (2 \pi t / 20)$. Figure 4 shows the mean displacement, the longitudinal and lateral variances of the plume. For small storativity, the mean and variances oscillate around the steady state case. However, for high strotativity $(S=0.1)$ the plume centroid is retarded due to the slow response of the groundwater head and consequently the Darcy's velocity. The same holds for the variance, however, the variance shows high oscillations when the plume travels towards the downstream boundary. It is important to note that the variance sometimes decreases (see Fig. 4 top right corner at late times). This behavior is due to the fact that particles at front of the plume may encounter negative velocities (moving towards upstream) whereas plume tail may be in a location with positive velocity (moving towards downstream). This may lead to shrinking of the plume and consequently reduction of the plume variance. This effect can be strongly shown in the dispersion coefficients $D_{x x}$ and $D_{y y}$ (Fig. 5). The dispersion coefficient is calculated as,

$$
D_{x x}(t)=\frac{1}{2} \frac{\mathrm{d} \sigma_{x x}^{2}(t)}{\mathrm{d} t}, \quad D_{y y}(t)=\frac{1}{2} \frac{\mathrm{d} \sigma_{y y}^{2}(t)}{\mathrm{d} t}
$$

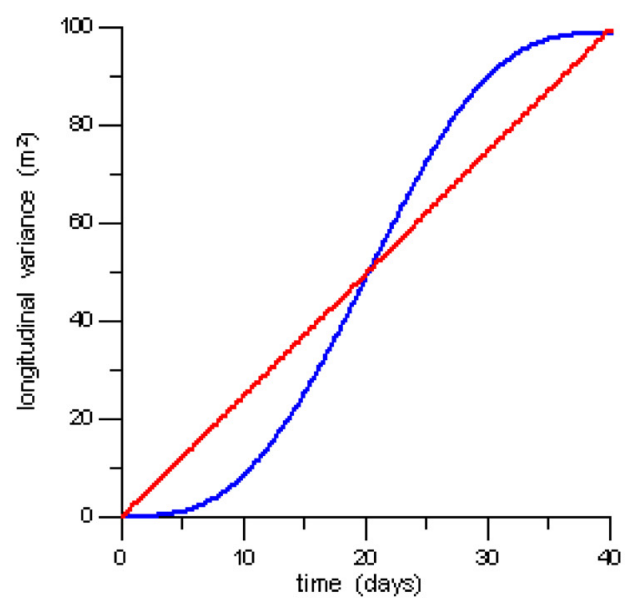

\section{The do wnstream bound ary is a periodical signal: \\ $20 \cos (2 \pi t / 40)+\cos (2 \pi t / 2)$}

unsteady state: fluctuating boundary

steady state (upstream level $=20 \mathrm{~m}$, downstream level $=0 \mathrm{~m}$ )

- 

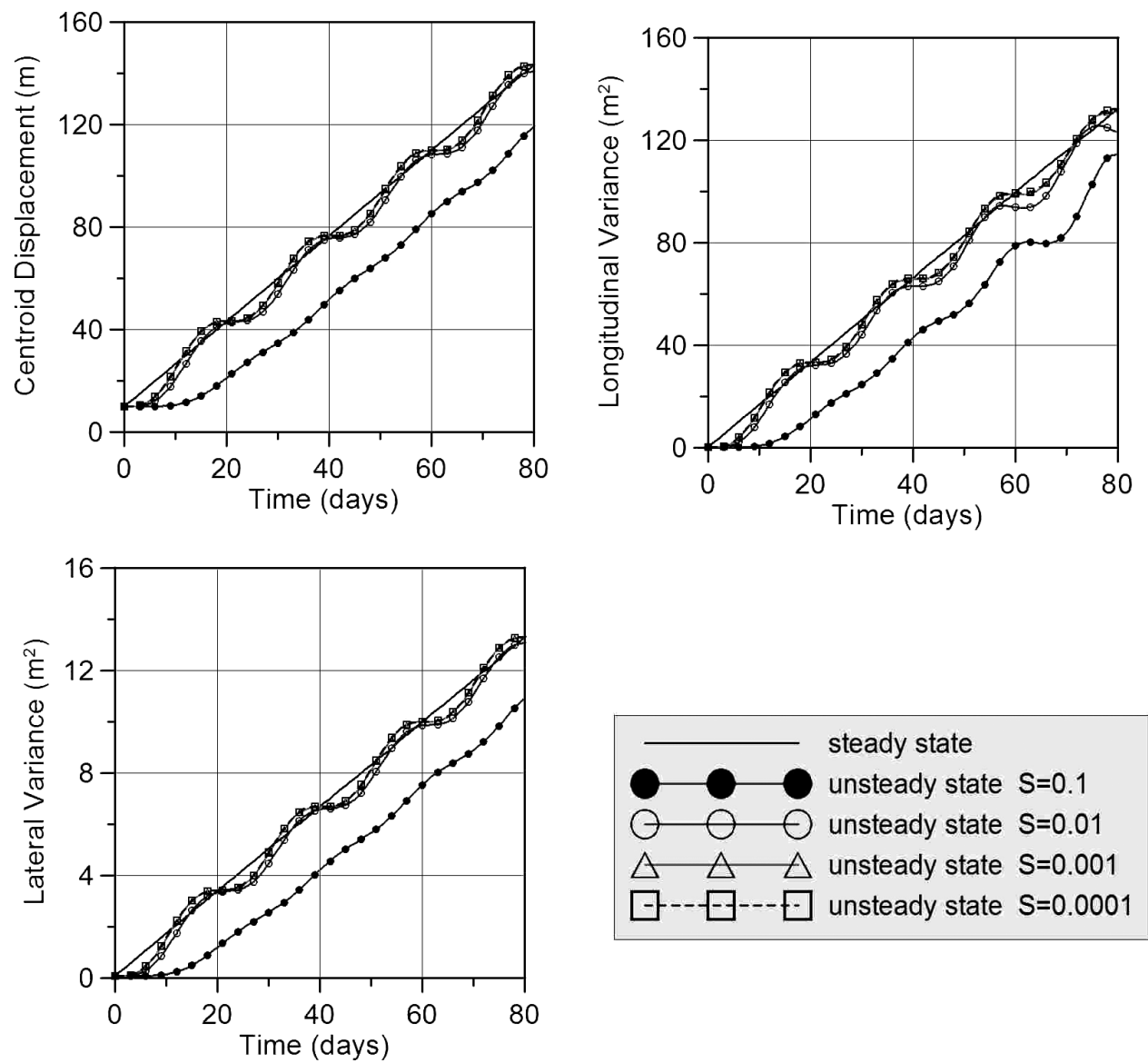

Figure 4 Spatial moments of the contaminant plume for different storativity values. The downstream water level fluctuates with a period of 20 days and the amplitude is $20 \mathrm{~m}$. Aquifers characteristics: length $=300 \mathrm{~m}$.
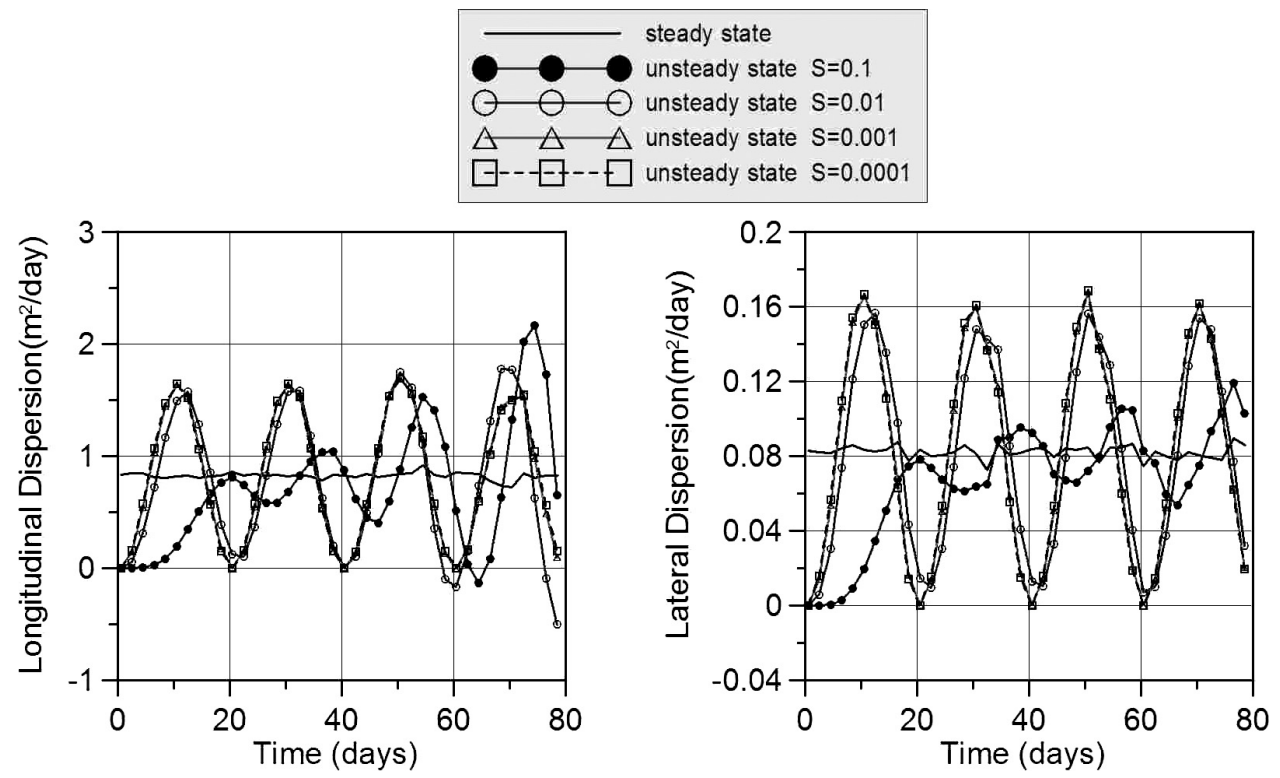

Figure 5 Temporal variation of the longitudinal and transverse dispersion coefficients for the different storativity values. The downstream water level fluctuates with a period of 20 days and the amplitude is $20 \mathrm{~m}$.

where, $\sigma_{x x}^{2}(t)$ is the plume second moment in the longitudinal direction and $\sigma_{y y}^{2}(t)$ is the plume second moment in the lateral direction.

The figure shows an amplification of the dispersion coefficient when the plume goes closer to the fluctuating boundary for $S=0.1$.

\subsection{Influence of the amplitude of fluctuations at the downstream boundary}

Solute transport is simulated for different amplitude of the fluctuation of the downstream boundary. Three amplitudes are studied: the upstream level is chosen at 1,3 , and $20 \mathrm{~m}$. The 
downstream level is a cosine function of amplitude of $\pm 1, \pm 3$ and $\pm 20 \mathrm{~m}$, respectively, oscillating around a specified level $0 \mathrm{~m}$, such that the mean head difference between boundaries is equal to 1,3 , and $20 \mathrm{~m}$ and the corresponding mean head gradients, $\left\langle J_{x}\right\rangle$, are $0.003,0.01$ and 0.06 , respectively. Results are compared with the corresponding steady state cases having the same mean head gradients (Figs 6 and 7). The storativity was chosen small ( $S=0.001$ ) such that the fluctuations don't die out inside the aquifer, so when the response of the aquifer is almost at maximum. The results show that oscillations occur around the steady state case. For small fluctuations (i.e $\left\langle J_{x}\right\rangle=0.003$ and 0.01 ), the oscillations are very close to the steady state case. In the steady state case, the dispersion coefficient can be computed as, $D_{0, x x}=\alpha_{\mathrm{L}}\left|V_{x}\right|$. Using a longitudinal dispersivity $\alpha_{\mathrm{L}}=0.5 \mathrm{~m}$ and Darcy's law, $V_{x}=(K / \varepsilon)\left(\Delta h / L_{x}\right)$, the dispersion coefficient is computed for head differences equal to 1,3 , and $20 \mathrm{~m}$. Results are $0.04,0.125$ and $0.83 \mathrm{~m}^{2} /$ day, respectively.
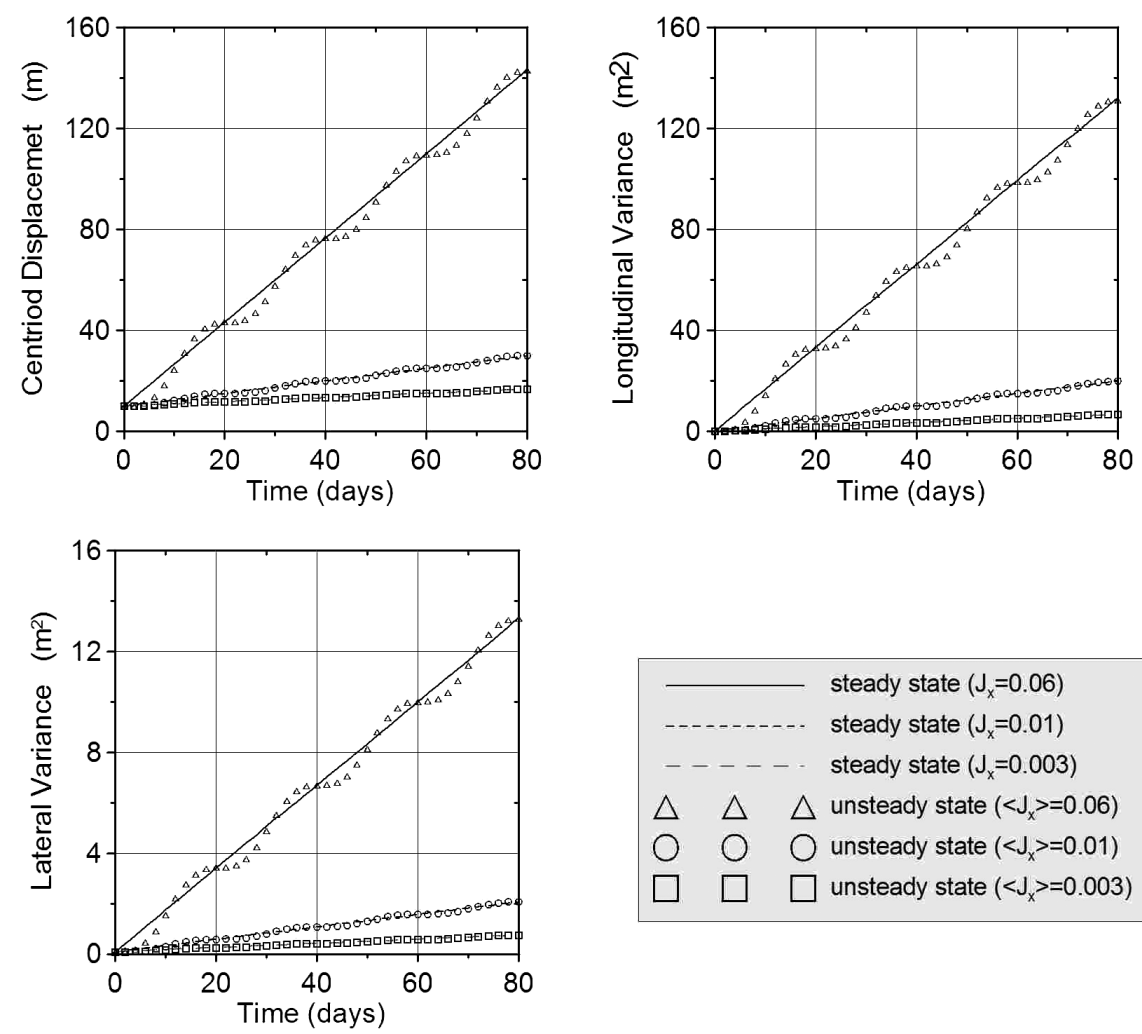

Figure 6 Evolution of plume spatial moments for three different mean head gradients $(0.003,0.01$ and 0.06$)$. The downstream water level fluctuates with a period of 20 days $(S=0.001)$.
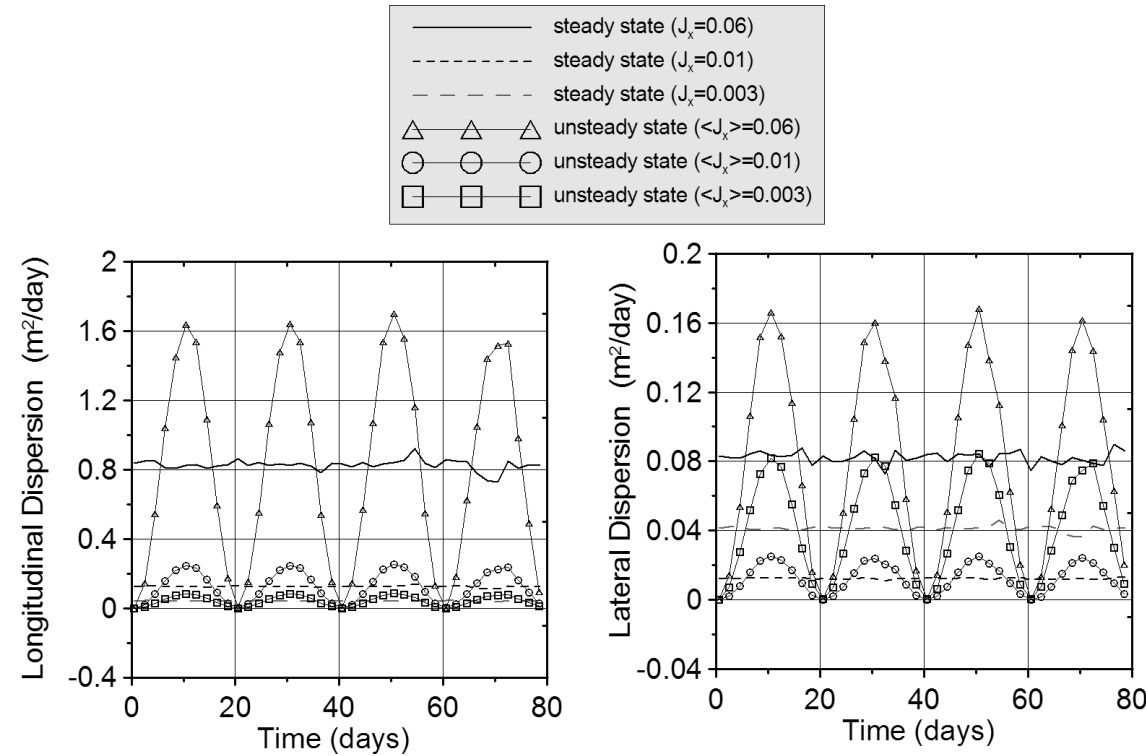

Figure 7 Temporal variation of longitudinal (left) and lateral (right) dispersion coefficients for the three different mean head gradients $\left(\left\langle J_{x}\right\rangle=0.003\right.$, 0.01 and 0.06 ) 


\section{Conclusions}

Comparison of the numerical model with analytical solutions has shown that the model provides a good representation of the aquifer response (hydraulic head) when oscillating flow conditions are imposed on the boundary. The response of a homogeneous aquifer under periodical forcing is controlled by the ratio $d / l=\sqrt{\pi S d^{2} / T P}$, which is the length of the aquifer over the penetration length, where $S$ is the storativity, $T$ the transmissivity and $P$ is the period of fluctuations. Thus $S, P$, and $T$ are factors that influence the propagation of oscillations as well as the decay of the amplitude of variation within the aquifer. It has been shown that when this ratio $d / l$ is small, the propagation of the oscillations and their amplitude are significant.

The amplitude of oscillations has strong impact on the transport of contaminant only if the amplitude of oscillations is relatively large. For relatively, small oscillations, results are close to steady state conditions. Transient conditions may become more important issue in coastal aquifers or tidal rivers when tidal amplitudes are relatively high (e.g. for the tidal parameters applied in this study). This can have a strong effect on the transport of solute or saltwater intrusion. This conclusion supports the one-dimensional results by Yim and Mohsen (1991).

Simulations under oscillating flow conditions have shown that the plume spatial moments fluctuate periodically around its corresponding steady state when the storativity tends to zero. However, when the storativity is relatively high, the plume spatial moments show delay when compared with the steady state case.

The longitudinal and lateral dispersion coefficients exhibit fluctuations around the steady state condition in the case of low strorativity. In the case of high storativity, fluctuations also occur around the steady state but with an amplification of the dispersion coefficients when the plume moves closer to the fluctuating boundary. This phenomenon is due to the fact that at high water level, groundwater flow can simultaneously reversed, introducing flow into the aquifer while the upstream part of the aquifer flows towards the water body (in the right side boundary). This leads to shrinking of the plume and consequently reduction in the plume size.

\section{References}

1. Ababou, R., Mclaughlin, D., Gelhar, L.W. and TOMPSON, A.T.B. (1989). "Numerical Simulation of Threedimensional Saturated Flow in Randomly Heterogeneous Porous Media”. Transport Porous Media 4, 549-565.

2. BEAR, J. (1979). Hydraulics of Groundwater, McGraw Hill, New York.

3. ElfeKi, A.M.M. (2003). "Transient Groundwater Flow in Heterogeneous Geological Formations". Mansoura Univ. Eng. J. 28(1), c58-c67.

4. Gelhar, L.W. (1993). Stochastic Subsurface Hydrology. Prentice Hall. Englewood Cliffs, NJ.

5. Gelhar, L.W. and Axness, C.L. (1983). "Threedimensional stochastic analysis of macrodispersion in aquifers. Water Resour. Res. 19(1), 161-180.

6. KinzelbaCH, W. and ACKerer, P. (1986). "Modélisation de la propagation d' un contaminant dans un cham d' écoulement transiotire". Hydrogéologie 2, 197-205 (in French).

7. LEBRETON (2003). Modelling Dispersion under Unsteady Groundwater Flow Conditions. Diplôme d'Ingenieur de I'Ecole de Physique du Globle I'Universtite Louis Pasteur, Strasbourg, France, 85p.

8. Ross, B. (1999). "Tidal Inflow to Aquifers". Water Resour. Res. 35(12), 3967-3968.

9. YIM, C.S. and MoHSEN, M.F.N. (1992). "Simulation of Tidal Effects on Contaminant Transport in Porous Media". Groundwater 30(1), 78-86.

10. Schirmer, M., Durrant, G.C., Molson, J.W. and Frind, E.O. (2001). "Influence of Transient Flow on Contaminant Biodegradation". Groundwater 39(2), 276-282.

11. SMith, L. and FreEZE, R.A. (1979). "Stochastic Analysis of Steady State Groundwater Flow in a Bounded Domain. 2. Two-dimensional Simulations". Water Resour. Res. 15(6), 1543-1559.

12. Townley, L.R. (1995). "The Response of Aquifers to Periodic Forcing". Adv Water Resour. 18(3), 125-146.

13. UfFinK, G.J.M. (1990). Analysis of dispersion by the random walk method. $\mathrm{PhD}$ thesis, Delft University of Technology, Delft, The Netherlands. 